\title{
A Photodetector-Synchronized Rapid Scanning Spectrometer with A Rotating Grating Directly Driven By A Synchronous Motor
}

\author{
Kuniyuki KITAGAWA* and Kyohei UsAmI \\ Department of Synthetic Chemistry, Faculty of Engineering, Nagoya University, \\ Furo-cho, Chikusa-ku, Nagoya 464 Japan \\ (Received June 16, 1986) \\ 北川 邦行*.宇佐美恭平 \\ 名古屋大学工学部合成化学科 名古屋市千種区不老町（广464） \\ (1986年 6 月16日受理)
}

\begin{abstract}
A new type of rapid scanning spectrometer was constructed for use in analytical atomic spectroscopy. The sine-bar and its driving system are disabled and the grating is driven directly by a synchronous motor. The wavelength synchronization is made by counting the photopulses generated by the combination of a small tungsten lamp, a phototransistor and a slotted aluminium disc which is attached to the shaft of the rotating grating. In an on-line and real-time mode, a variety of measurements can be achieved by a dedicated microcomputer. The basic analytical performance was evaluated and some applications are demonstrated.
\end{abstract}

\section{Introduction}

In recent years, a variety of computercontrolled SSS (Sequential Slew Scanning) spectrometers have become commercially available for multielement analysis with ICP (Inductively Coupled Plasma) as the excitation source $[1,2]$. Compared to polychromators, they allow line selection at any desired wavelength and consequently enable choice of the optimum analytical line for different analytical conditions such as operational conditions of the excitation source and spectral interferences. Owing mainly to the wavelength scanning procedure, however, the analysis time is longer than that of the polychromator as the number of the elements to be determined increases. This is an unfavourable

* Author to whom correspondence should be sent. situation when the sample volume available is small. Such a case is not unusual when biological samples are encountered. It would therefore be useful to scan more rapidly. To develop a high speed SSS spectrometer, it is necessary to overcome the effect of inertia and friction in the mechanical system of wavelength scanning. Another problem of the conventional SSS spectrometers is that the regular wavelength re-calibration is necessary.

Numerous papers have appeared on several spectrometer types using image sensors such as photodiode array [3], SIT (Silicon Intensified Target) tubes [4] and Vidicon tubes [5]. From the standpoint of simultaneous detection and absolute wavelength correspondence, these spectrometers are preferable. To date, however, the sensitivity obtainable by the detectors is less than that of the conventional photomultiplier tubes, particularly at shorter wave- 
lengths. In addition, the resolution and wavelength coverage should be compromised because of the limited window size of the detectors.

Several papers have dealt with the development and applications of an oscillating mirror rapid scanning spectrometer [6-8]. However, its wavelength coverage is not satisfactory.

In an earlier paper [9], we described a tentatively constructed new type of rapid scanning spectrometer without the sine-bar and its driving system. In this paper, we will describe basic performance of this spectrometer for the use in analytical atomic spectroscopy. Some typical applications to demonstrate the features will also be presented.

\section{Experimental}

\section{Apparatus}

Figure 1 shows the schematic diagram of the rapid scanning spectrometer and electronic circuit constructed for this study. The monochromator is a modified Hitachi Czerny-Turner type dual monochromator (used in a Hitachi Model 300) with a focal length of $1.2 \mathrm{~m}$, and two gratings of 1200 grooves/mm and a blaze wavelength of $250 \mathrm{~nm}$.

The sine-bar in the wavelength-drive mechanisms for one of the gratings is removed and a synchronous motor with an aluminium disc of $470 \mathrm{~mm}$ in diameter and $10 \mathrm{~mm}$ in thickness is mounted on the grating shaft

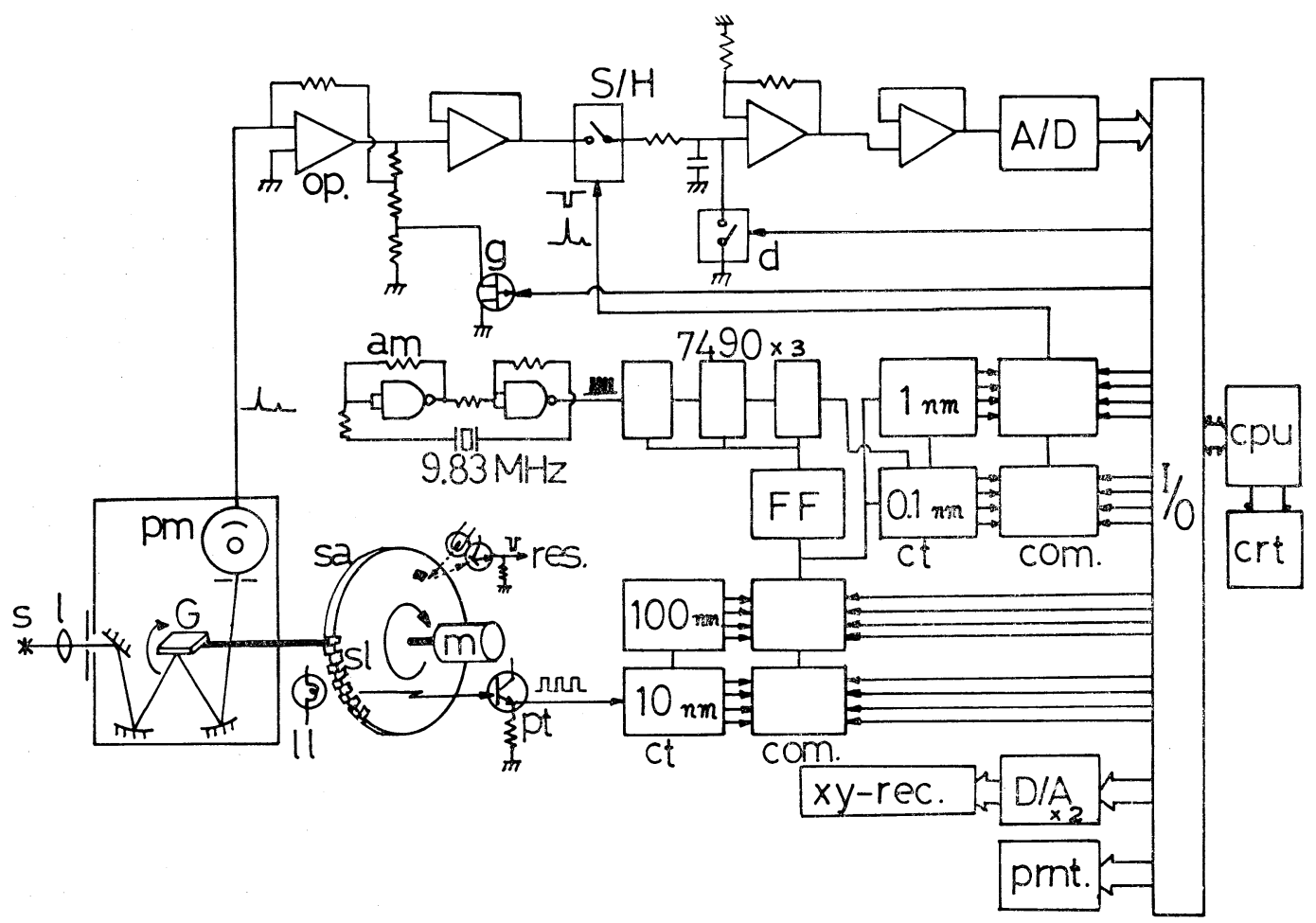

Fig. 1 Schematic diagram of the rapid scanning spectrometer and electronic circuits.

s: light source, 1: lens, G: rotating grating, pm: photomultiplier tube (HTV R928), 11: tungsten lamp with converging lens, sa: synchronization aluminium disc, s1: slots, $\mathrm{m}$ : synchronous motor, pt: phototransistor, res. : reset pulse, ct: BCD counters, com : comparator, FF : flip flop IC (SN7473), am: astable multivibrator (SN7400), op.: operational amplifier (LF356), g: gain-switching transistor (2SJ74), S/H: sample and hold circuit, d: capacitordischarge switch (4016), A/D : analog to digital converter (AD574KD), I/O: parallel input and output interface, cpu: central processing unit (Z80A), crt: character display, D/A : digital to analog converter (DAC80 CBI-V), prnt: discharge printer. 
which is supported through a ball bearing mount. The grating and the aluminium disc are directly driven (DD) to rotate at 30 r.p.m. Twenty-two slots ( $1 \mathrm{~mm}$ width, $5 \mathrm{~mm}$ height and $2 \mathrm{~mm}$ pitch) are cut on a circular arc of the aluminium disc. A phototransistor and a small tungsten lamp with a converging lens are located in front of and behind the aluminium disc, respectively. The radiation emitted from the lamp passes through the slots and reaches the phototransistor to generate pulses when the aluminium disc revolves. The period of the pulse sequence is $2.7 \mathrm{msec}$ and corresponds approximately to $10 \mathrm{~nm}$ in wavelength. In order generate the pulses to reset the pulse counters, another phototransistor and lamp are placed in front of the aluminium disc. The phototransistor detects the radiation reflected on the disc surface. On the surface, a dark tape is attached to produce a negative logic pulse.

The wavelength synchronization is made by the electronic circuit in conjunction with the microcomputer, as follows. The pulses from the phototransistor are counted by two $\mathrm{BCD}$ counters (SN4160) to give the upper two digits of 10 and $100 \mathrm{~nm}$. In order to give the lower two digits of 0.1 and $1 \mathrm{~nm}$, clock pulses are produced by an oscillator consisting of two NAND gates (SN7400) and a quartz crystal. The clock pulses are converted into $27 \mu$ sec pulses $(0.1 \mathrm{~nm})$ by decade and divide-by-five counters (SN7490), and subsequently counted by the other two BCD counters (SN74160) to give the digits of 0.1 and $1 \mathrm{~nm}$. At the beginning of every rotation of the grating, the reset pulse clears all of the pulse counters.

The radiation emitted from the light source is diffracted by the rotating grating and consequently the wavelength of the monochromatic radiation emerging from the exit slit is changing continually. Thus, a spectrum is obtainable instantaneously. After the conversion of photocurrent to voltage, the signals are passed to the sample and hold circuit. The analogue switch (C-MOS4051) is controlled to open and close to sample and hold the signal associated with the desired wavelength as described below.

The digital outputs of four digits $(4 \times 4=16$ bits) from the $\mathrm{BCD}$ counters are applied to one side of the input terminals of the digital comparators (SN7485). On the other side is the reference $\mathrm{BCD}$ information in four digits, given by the microcomputer (Sharp $\mathrm{MZ}-80 \mathrm{~K}$, Z80A cpu and clock frequency of $4 \mathrm{MHz}$ ) through the parallel I/O interface (Sharp Universal I/O Card). The reference BCD information involves the wavelength of interest. At the moment when all of the digits for $0.1,1$, 10 and $100 \mathrm{~nm}$ agree between both sides of the input terminals of the comparators, a sampling pulse is generated. The pulse is passed to the sample and hold circuit and closes the analogue switch to integrate the signal associated with the desired wavelength. Subsequently, the sampling pulse opens again the analogue switch to hold the accumulated signal. The sampling time, which determines the wavelength window, is regulated by the monostable multivibrator (SN74121) and can be changed optionally.

With appropriate program, the microcomputer can present the reference $\mathrm{BCD}$ wavelength information in various modes. Thereby, the spectral intensity at any desired wavelength can be measured either intermittently or successively. If the sampling pulses are generated successively or neighbour-to-neighbour wavelength, an entire spectrum can be obtained. With a 360 rotation of the grating, spectra of all diffraction orders from the zero to nth are measurable, where $\mathrm{n}$ is the natural number.

The sampled and integrated signal is passed to the 12 bit A/D converter (Analog Device $\mathrm{A} / \mathrm{D} 574 \mathrm{KD}$ ) and to the cpu through the $\mathrm{I} / \mathrm{O}$ interface. It is then processed and/or stored in the memory bank. In order to extend the dynamic range of the $\mathrm{A} / \mathrm{D}$ and $\mathrm{S} / \mathrm{H}$, autoranging of the photomultiplier tube preaplifier is employed. The preamplifier gain is switched by the cpu through the FET (2SJ74) which is located in the feedback circuit of the preamplifier.

Figure 2 demonstrates the typical flow chart of the microcomputer program. The program is composed of two parts. The left is the main routine written in BASIC and the right the subroutine written in Z80 machine language. The subroutine runs in $0.2 \mathrm{sec}$ and sets up the procedures to switch the preamplifier gain, to set the reference wavelength 

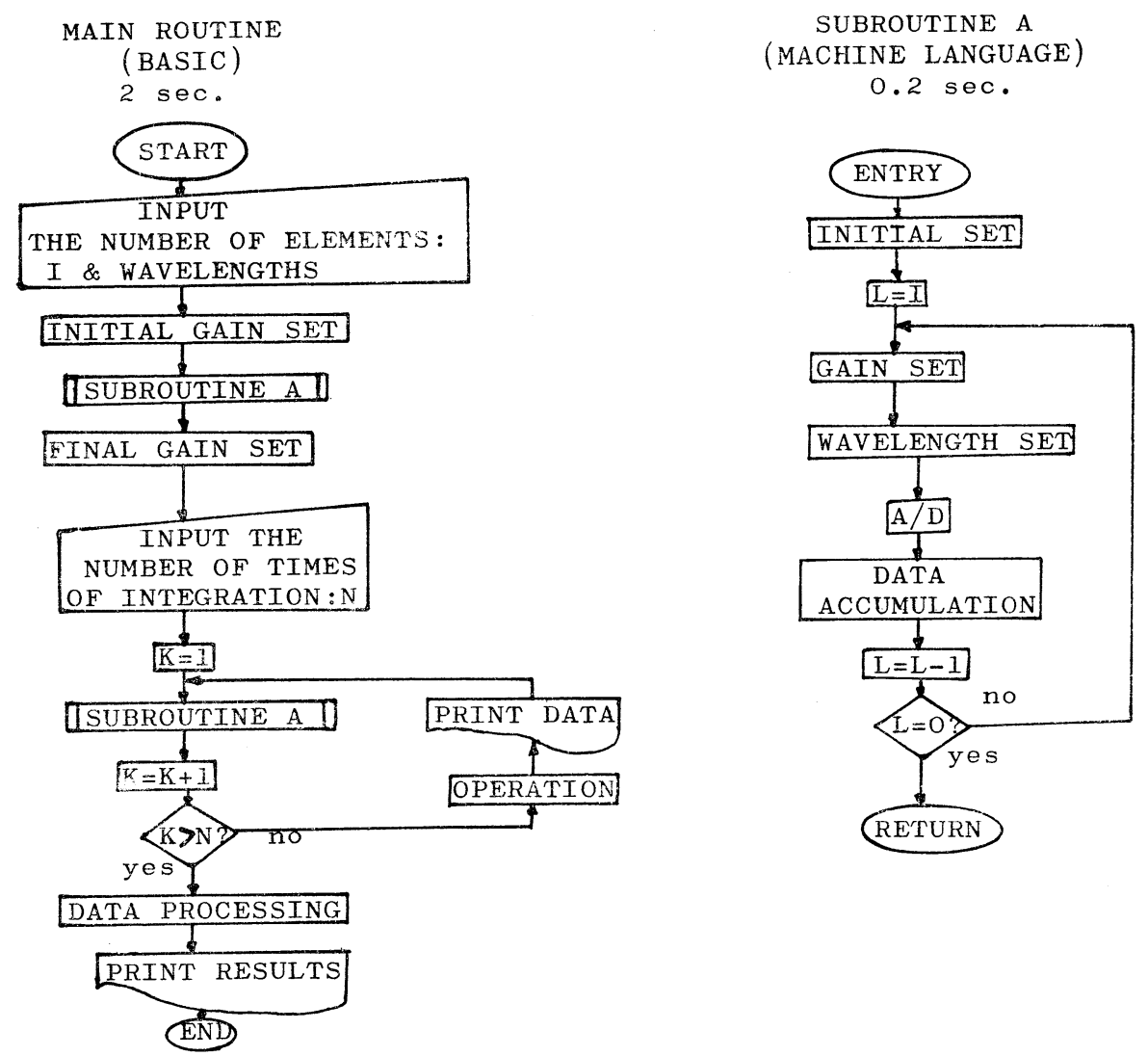

Fig. 2 Flow charts of typical programs for microcomputer. The mode of multielement measurements as an example.

information in the comparator, to control the sample and hold circuit, to start the A/D converter and to acquire the digital data. The BASIC program involves initializing, a loop for real-time processing and a section for post processing. In initializing, such parameters as the number of the elements to be measured, the data acquisition mode, the wavelengths, the number of times of integration, etc. are set. Information setting the preamplifier gain is also acquired in here. During the first revolution of the grating, the cpu determines if the acquired spectral intensity exceeds full scale of the $\mathrm{A} / \mathrm{D}$ converter $(10 \mathrm{~V}$ in analogue voltage or 4095 in digital form) and decides whether the FET gain switch should be closed or opened.

The main routine loop includes the machine language subroutine and real-time processings such as integration, CRT display, printing on the high-speed printer, simple arithmetic calculation, etc. The post processing program deals with complicated arithmetic calculations, figure drawing on the $x-y$ recorder, list preparation, etc., for which a relatively longer time is required than for the real-time data logging.

Other instruments used for this study are listed in Table 1, together with their operating conditions. Hollow cathode lamps and CMP (capacitively coupled microwave plasma) were employed as the light source for the wavelength calibration and the sample excitation, respectively. The CMP was modified so as to introduce the sample aerosol through a hole drilled along the central axis of the aluminium discharge electrode [10]. An ultrasonic nebulizer $(1.6 \mathrm{MHz})$-desolvation system was constructed for the sample introduction. In order to allow efficient desolvation, a double- 
Table 1 Experimental apparatus and settings

\begin{tabular}{|c|c|}
\hline $\begin{array}{l}\text { Capacitively coupled microwave plasma } \\
\text { microwave frequency } \\
\text { anode current of magnetron } \\
\text { field current of magnetron } \\
\text { microwave power } \\
\text { plasma-forming gas } \\
\text { plasma sheath gas }\end{array}$ & $\begin{array}{l}\text { Hitachi Model } 300 \\
2450 \pm 25 \mathrm{MHz} \\
300 \mathrm{~mA} \\
400 \mathrm{~mA} \\
\text { ca. } 350 \mathrm{~W} \\
0.4 \mathrm{lmin}^{-1} \mathrm{Ar} \\
0.6 \mathrm{Imin}^{-1} \mathrm{He}\end{array}$ \\
\hline $\begin{array}{l}\text { Spectrometer } \\
\text { Entrance slit width } \\
\text { Exit slit width } \\
\text { Photomultiplier tube }\end{array}$ & $\begin{array}{l}\text { Hitachi Model 300, Dual monochromator of } \\
\text { Czerny-Turner mount, } f=120 \mathrm{~cm} \text {, modified } \\
80 \mu \mathrm{m} \\
80 \mu \mathrm{m} \\
\text { HTV R928 }\end{array}$ \\
\hline Measurement position of plasma & $3-13 \mathrm{~mm}$ above the discharge electrode \\
\hline $\begin{array}{l}\text { Nebulizer } \\
\text { Power supply for the vibrator }\end{array}$ & $\begin{array}{l}\text { A disc type of ultrasonic vibrator, TDK, } f=1.65 \\
\pm 0.05 \mathrm{MHz} \text {, the back side water-cooled } \\
\text { Laboratory-made self-tuning oscillator with } 4 \\
\text { transistors, ca. } 20 \mathrm{~W} \text { max. }\end{array}$ \\
\hline $\begin{array}{l}\text { Desolvation system } \\
\text { Heating tube } \\
\text { Condenser } \\
\text { Sample feeding rate }\end{array}$ & $\begin{array}{l}\text { Pyrex, } 11 \mathrm{~mm} \text { i.d., } 200 \mathrm{~mm} \text { length, heated to } \\
190^{\circ} \mathrm{C} \text { by nichrome wire } \\
\text { Laboratory-made double-wall type, inner tube of } \\
6 \mathrm{~mm} \text { o.d., outer tube of } 11 \mathrm{~mm} \text { i.d. } \\
1 \mathrm{mlmin}-1\end{array}$ \\
\hline $\begin{array}{l}\text { Hollow cathode lamps } \\
\text { Discharge current }\end{array}$ & $\begin{array}{l}\text { Hitachi, Hamamatsu TV, Westinghouse } \\
5-15 \mathrm{~mA}\end{array}$ \\
\hline Storage oscilloscope & Kikusui Model 5510ST \\
\hline $\mathrm{X}-\mathrm{Y}$ recorder & Watanabe Sokki, Model WX4402 \\
\hline $\begin{array}{l}\text { Microcomputer } \\
\text { Printer } \\
\text { BASIC interpreter } \\
\text { Machine language } \\
\text { I/O system }\end{array}$ & $\begin{array}{l}\text { Sharp } \mathrm{MZ}-80 \mathrm{~K} \\
\text { Sharp } \mathrm{MZ}-80 \mathrm{P} 2 \\
\text { Sharp } \mathrm{SP}-5030 \\
\text { Sharp Machine Language } \\
\text { Sharp } \mathrm{MZ}-80 \mathrm{I} / \mathrm{O}\end{array}$ \\
\hline
\end{tabular}

wall condenser was manufactured [11].

\section{Reagents}

Standard stock solutions of $1000 \mathrm{mg} / \mathrm{l}$ were prepared from pure metals $(>99.9 \%)$ or salts (chloride or nitrate of analytical grade) and the test solutions were made immediately before use. The acidity of all solutions was adjusted to $0.1 \mathrm{~N}$ with hydrochloric or nitric acid.

\section{Results and Discussion}

Full-order scanning with the rotating grating

Figure 3 demonstrates the trace of transient spectrum recorded on the storage oscilloscope,

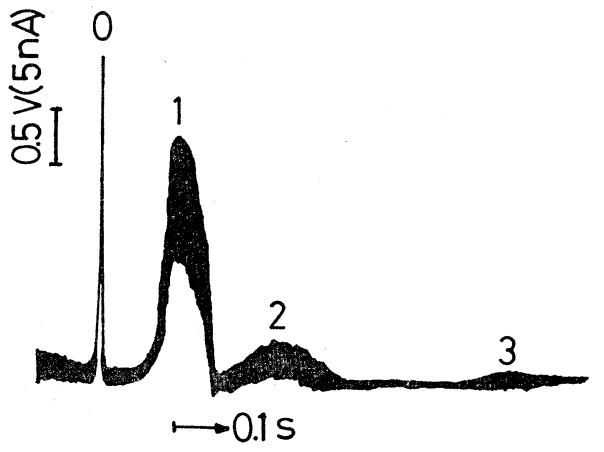

Fig. 3 Multi-order spectra of incandescent light recorded on the storage oscillo. scope screen. 
using a small tungsten lamp as the light source. It can be seen from the figure that spectrum from the incandescent lamp is scanned from the zero to third order within 1 second. The first order spectrum that is most often used for routine analysis requires only ca. $0.2 \mathrm{sec}$ to scan from 200 to $800 \mathrm{~nm}$. Thus, all orders can be observed sequentially during one grating rotation. Any desired order spectrum can be selected easily with a computer program.

\section{Wavelength fluctuation and reproducibility}

Figure 4 shows the relative time fluctuation between the sampling pulse and the spectral peak of the $\mathrm{Cu}[\mathrm{I}]$ line at $324.75 \mathrm{~nm}$. The trace were recorded on the storage oscilloscope for every rotation of the grating, using the negative edge of the sampling pulse as the external trigger. As seen from the figure, the fluctuation range of the peak maximum is $\pm 9 \mu \mathrm{sec}$, or $\pm 0.03 \mathrm{~nm}$. This is not so large compared with the reciprocal linear dispersion of the monochromator used $(0.6 \mathrm{~nm} / \mathrm{mm}$ or $0.06 \mathrm{~nm}$ with $0.1 \mathrm{~mm}$ slit width). The fluctuation is mainly attributable to the slight variation in the angular velocity of the grating rotation during the interval between the $10 \mathrm{~nm}$ pulses, because each of the 0.1 and $1 \mathrm{~nm}$ pulses is not synchronized with the external trigger pulse from the aluminium disc but internally generated.

Figure 5 shows the wavelength reproduci-

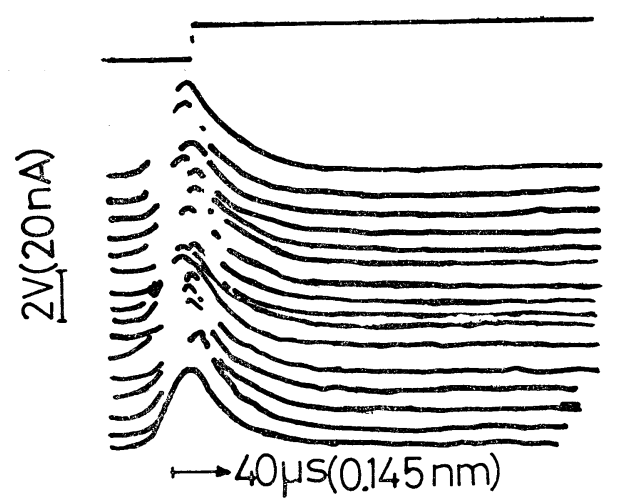

Fig. 4 Transient spectrum of $\mathrm{Cu}[\mathrm{I}] 324.754 \mathrm{~nm}$ recorded for every rotation of the grating by the storage oscilloscope.

The upper trace: the sampling pulse used as the triggering signal.

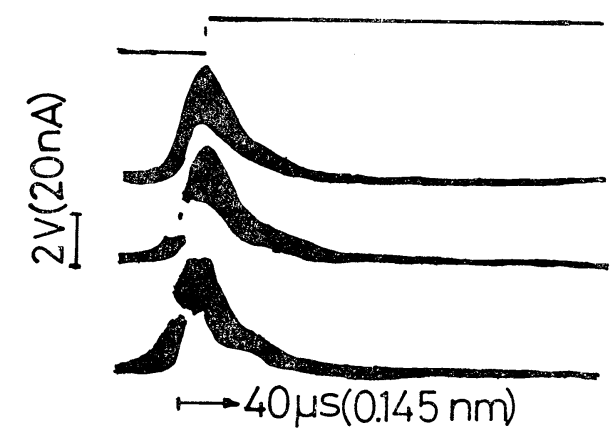

Fig. 5 Transient spectra of $\mathrm{Cu}[\mathrm{I}] 324.754 \mathrm{~nm}$ superimposed 100 times on the oscilloscope screen.

bility. Each of the three traces consists of the transient peaks which are superimposed on the screen of the storage oscilloscope for 100 rotations of the grating. After the first trace was recorded for 100 rotations, the grating rotation was stopped. Subsequently, the rotation was restarted and after its stabilization, the second trace was recorded for 100 rotations. It can be seen that the wavelength centers of the peak maxima lie within the wavelength fluctuation.

Relation between the comparator set and wavelength

For the spectrometer constructed in this study, the wavelength adjustment is not routinely necessary since the wavelength synchronization is directly related to the grating angle. However, the calibration between the comparator set and the wavelength should be made once after construction. By using the hollow cathode lamps of 11 elements as the emission line source, calibration was made for 12 lines where the comparator set allowed almost complete coincidence of the sampling pulse with the spectral signal peak. The results are listed in the first and second columns of Table 2. By setting the number of the second column in the comparator, the microcomputer can pick up any line at the wavelength identical with the first column.

For convenience in setting an arbitrary wavelength not listed in Table 2 , the relationship between the comparator set and the wavelength is expressed in the form of a quadratic regression curve utilizing the values in the first and second columns : $s=9.8191 \times$ 
Table 2 Relation between the comparator set and wavelength

\begin{tabular}{|c|c|c|c|c|c|c|c|}
\hline \multirow{2}{*}{\multicolumn{2}{|c|}{$\lambda(\mathrm{nm})$}} & \multirow{2}{*}{$s_{0}$} & \multirow{2}{*}{$s$} & \multicolumn{2}{|c|}{$\Delta s$} & \multicolumn{2}{|c|}{$\Delta \lambda(\mathrm{nm})$} \\
\hline & & & & $\mathrm{a}$ & $\mathrm{b}$ & $\mathrm{a}$ & $\mathrm{b}$ \\
\hline $\mathrm{Hg}$ & I 253.652 & 2599 & 2599.20 & 0 & 0 & 0 & 0 \\
\hline $\mathrm{Mn}$ & I 279.482 & 2820 & 2821.79 & +1 & +2 & +0.116 & +0.231 \\
\hline $\mathrm{Pb}$ & I 283.306 & 2856 & 2854.86 & -2 & -1 & -0.231 & -0.115 \\
\hline $\mathrm{Mg}$ & I 285.213 & 2873 & 2871.35 & -2 & -2 & -0.231 & -0.231 \\
\hline & I 306.772 & 3063 & 3058.38 & -5 & -5 & -0.575 & -0.575 \\
\hline $\mathrm{Al}$ & I 309.271 & 3086 & 3080.12 & -6 & -6 & -0.690 & -0.690 \\
\hline $\mathrm{Cu}$ & I 324.754 & 3214 & 3215.08 & +1 & +1 & +0.115 & +0.115 \\
\hline $\mathrm{Cu}$ & I 327.396 & 3238 & 3238.16 & 0 & 0 & 0 & 0 \\
\hline $\mathrm{Al}$ & I 396.153 & 3844 & 3843.54 & -1 & 0 & -0.113 & 0 \\
\hline $\mathrm{Mn}$ & I 403.076 & 3904 & 3905.00 & +1 & +1 & +0.113 & +0.113 \\
\hline $\mathrm{Ca}$ & I 422.673 & 4081 & 4079.51 & -2 & -1 & -0.224 & -0.112 \\
\hline $\mathrm{Sr}$ & I 460.733 & 4420 & 4420.58 & 0 & +1 & 0 & +0.111 \\
\hline
\end{tabular}

$\lambda$; the wavelength [15]

$s_{0}$; the comparator set experimentally determined

$s$; the comparator set calculated with the quadratic regression curve (see the main text)

$\Delta s ; s-s_{0}$

$\Delta \lambda$; the wavelength error corresponding to $\Delta s$ (see the main text)

a ; disregarding the fraction below the decimal point

$\mathrm{b}$; counting fractions 5 and over as a unit and cutting away the rest

$10^{-4} \lambda^{2}+8.09403 \lambda+482.96$ (Eq. 1 ) where $s$ is the comparator set and $\lambda$ the wavelength in $\mathrm{nm}$. In table 2, the following parameters are listed also for evaluation of this equation: (1) the comparator set $s$, calculated by Eq. 1, (2) the error of the calculated set $s$ from the experimentally determined set $s_{0}, \Delta s$ for the two cases (a; disregarding the fraction below the decimal point and $\mathrm{b}$; counting fractions 5 and over as a unit and cutting away the rest) and (3) the wavelength error corresponding to $\Delta s$, $\Delta \lambda$ for the two cases, calculated by the equation $\Delta \lambda=\Delta s /\left(2 \times 9.8191 \times 10^{-4} \lambda+8.08403\right)(\mathrm{Eq} .2)$ which is derived from Eq. 1 by differentiating $s$ with respect to $\lambda$ and making the approximations that $\Delta s / \Delta \lambda=d s / d \lambda$. For either of two cases, the wavelength errors lie almost within a range of $\pm 0.2 \mathrm{~nm}$ except for the $\mathrm{Bi}$ and $\mathrm{Al}$ lines. Taking into account that the minimum digit set is $0.1 \mathrm{~nm}$, the range of $\pm 0.2 \mathrm{~nm}$ is reasonable, but insufficient for AES measurement. A promising way to minimize the wavelength error is to make finer the slots of the alminium disc. The extraordinarily large errors for the $\mathrm{Bi}$ and $\mathrm{Al}$ lines are probably caused by mechanical irregularity in the slot spacing. This can introduce errors in the pulse counting process because the 0.1 and $1 \mathrm{~nm}$ digits are synchronized by counting the pulses for the internal generator, the period of which is constant. On the other hand, the quadratic regression expression (Eq.1) does not account for these errors, leading to the large errors. Thus, the least significant digit must be made more precise by counting directly more precise pulses from the synchronizing disc.

\section{Sensitivity}

Figure 6 illustrates the dependence of the sensitivity or the peak magnitude of the signal on the angular velocity of the grating rotation. The upper peaks are the sampling pulses and the lower the photocurrents. Each of the photocurrent peaks consists of those induced by the radiation of all different orders. As the light source, the Mn hollow cathode lamp was used. The traces were recorded in the following manner. The power supply for the synchronization motor was switched off and the grating rotation slowed to stop. During the slowing period, the photocurrents and the sampling pulses were registered on the storage oscilloscope. The first peak corresponds to that measured when the grating 
rotates at 30 r.p.m. The height of the fourth and last peaks almost equals that observed when the grating is at rest. The height of the first peak is ca. $50 \%$ of that of the ast peak. Therefore, as far as the peak height

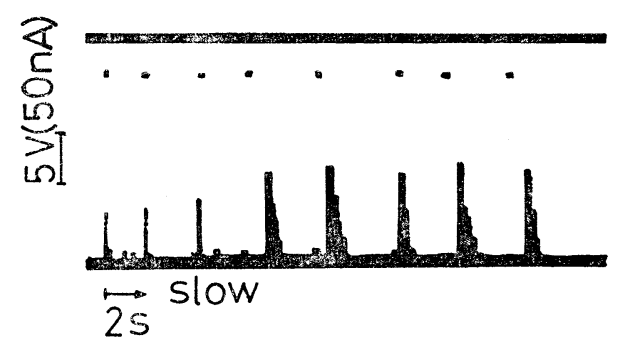

Fig. 6 Dependence of the peak amplitude of photocurrents on the angular velocity of the grating rotation.

The upper trace: the sampling pulse, the lower: the photocurrents. To the right, the grating rotation was decelerated. The Mn hollow cathode lamp was used as the ight source. is concerned, the loss due to the short time duty in the rapid scan is not so significant in this case. For weaker source intensity, however, it is expected that the loss is large.

Integration

In addition to the problem described above,

Table 3 Effect of integration on the relative starndard deviation of intensity

\begin{tabular}{|c|c|c|c|c|}
\hline \multirow{2}{*}{$\frac{\text { Integration (times }}{\text { Wavelength }(\mathrm{nm})}$} & \multicolumn{4}{|c|}{$\begin{array}{l}\text { Relative standard } \\
\text { deviation }(\%)\end{array}$} \\
\hline & 1 & 10 & 50 & 100 \\
\hline Mn I 279.482 & 12.4 & 6.0 & 1.9 & 1.5 \\
\hline Mn I 403.076 & 5.5 & 4.2 & 1.9 & 1.9 \\
\hline $\mathrm{Cu}$ I 324.754 & 7.8 & 5.2 & 2.3 & 2.5 \\
\hline $\mathrm{Cu}$ I 327.396 & 17.0 & 4.4 & 3.0 & 1.8 \\
\hline
\end{tabular}

The H.C. L. current $=10 \mathrm{~mA}$ for the $\mathrm{Mn}$ and $\mathrm{Cu}$ lamps. Each of standard deviations was calculated from four and five replicated integrations for the $\mathrm{Mn}$ and $\mathrm{Cu}$ lines, repectively.
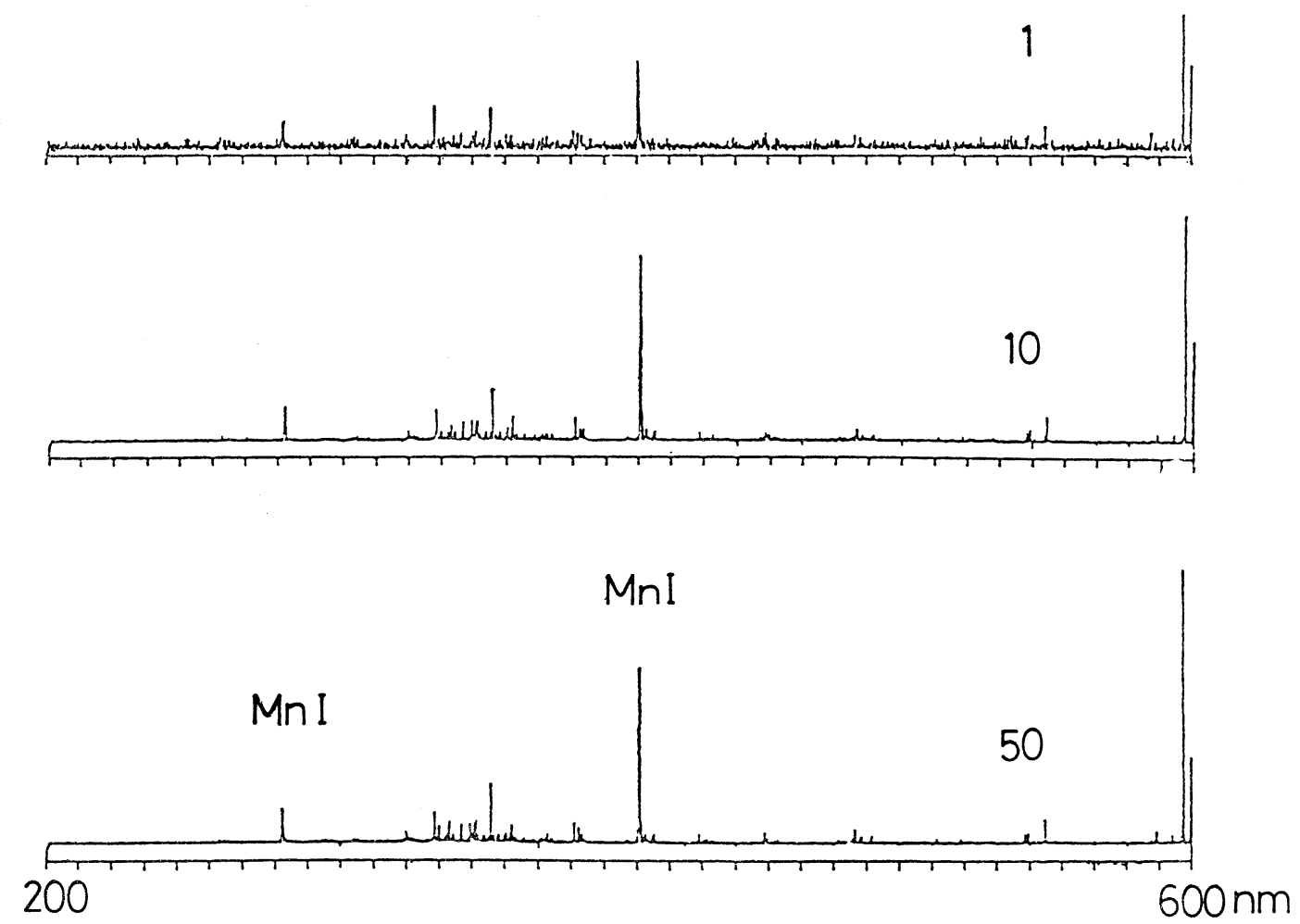

Fig. 7 Effect of integration on the $\mathrm{S} / \mathrm{N}$ ratio for the spectra of the $\mathrm{Mn}$ hollow cathode lamp. The numbers indicate that of time of integration. The width of the sampling pulse : $54 \mu \mathrm{sec}$, or $0.2 \mathrm{~nm}$. 
there is another problem in the rapid scan, which is caused by the short time duty: large fluctuation in the number of photons sampled during the short sampling time, resulting in large fluctuation in the spectral peak height. The fluctuation can be reduced by integrating and averaging the photocurrents with respect to the grating rotation.

Table 3 lists the r.s.d. in the integrated and averaged spectral intensity of the four lines for the different number of grating rotation. The $\mathrm{Mn}$ and $\mathrm{Cu}$ hollow cathode lamps were used as the light source. Every r.s.d. decreases as the number of the grating rotation increases. Figure 7 demonstrates the effect of the integration and averaging on the $\mathrm{S} / \mathrm{N}$ ratio for the entire spectrum from 200 to $600 \mathrm{~nm}$, obtained with the Mn hollow cathode lamp as the light source. It is obvious that the $\mathrm{S} / \mathrm{N}$ ratio increases as the number of integrations increases.

\section{Some applications}

Table 4 list the typical result of multielement measurements. The CMP was used as the excitation source. Along with every rotation of the grating, the spectral intensity values can be printed out, in the on-line and real-time mode. Here are listed the values at intervals of 10 integrations. The blank measurements also are made and printed out.

In the multielement analysis with the conventional slow scanning spectrometer, there is the difficult problem for a small sample size: the long scanning time makes it difficult to measure all of the lines of the elements to be analyzed during the sample consumption time. On the other hand, the rapid scanning spectrometer allows to scan the entire spectrum region with the sample size, at least supporting $2 \mathrm{sec}$, though the $\mathrm{S} / \mathrm{N}$ ratio is low. The integration to improve the $\mathrm{S} / \mathrm{N}$ ratio can be carried out arbitrarily until the full consumption of the sample or allowed to stop at any integration time.

By altering the computer program, the processing mode can be optionally changed. As an example, Table 5 lists the results for the measurement of excitation temperature of $\mathrm{Mn}$ atoms in the hollow cathode lamp used as the light source. The well-known Ornstein's twoline method [12] is applied. The observed
Table 4 Multi-element measurement with the CMP

\begin{tabular}{|c|c|c|c|c|c|c|c|c|c|c|c|c|}
\hline$\#$ & $\mathrm{Zn}$ & $\mathrm{Cd}$ & $\mathrm{Mn}$ & & $\mathrm{Cu}$ & $\mathrm{Ni}$ & Co & $\mathrm{Al}$ & $\mathrm{Mr}$ & & $\mathrm{Pb}$ & $\mathrm{Cr}$ \\
\hline 1 & 65 & 140 & 140 & & 46 & 208 & 85 & 121 & 14 & & 40 & 59 \\
\hline 10 & 68 & 134 & 140 & & 59 & 212 & 110 & 100 & 12 & & 40 & 63 \\
\hline 20 & 66 & 134 & 140 & & 50 & 216 & 116 & 99 & 12 & & 40 & 63 \\
\hline 30 & 65 & 135 & 140 & & 47 & 216 & 117 & 97 & 12 & & 41 & 63 \\
\hline 40 & 66 & 136 & 143 & & 49 & 217 & 117 & 99 & 12 & & 41 & 63 \\
\hline 50 & 65 & 136 & 140 & & 46 & 216 & 113 & 99 & 12 & & 40 & 63 \\
\hline 60 & 64 & 136 & 141 & & 44 & 215 & 116 & 101 & 12 & & 39 & 62 \\
\hline 70 & 64 & 135 & 141 & & 42 & 213 & 116 & 100 & 12 & & 40 & 61 \\
\hline 80 & 64 & 135 & 140 & & 39 & 210 & 115 & 98 & 12 & & 40 & 61 \\
\hline 90 & 63 & 135 & 140 & & 37 & 208 & 116 & 97 & 12 & & 40 & 61 \\
\hline 100 & 63 & 134 & 139 & & 35 & 206 & 116 & 96 & 12 & & 39 & 61 \\
\hline \multicolumn{13}{|c|}{ B. G. } \\
\hline 1 & 26 & 43 & 53 & 82 & 81 & 94 & 25 & 33 & 30 & 16 & 33 & \\
\hline 10 & 29 & 28 & 68 & 83 & 96 & 86 & 25 & 30 & 33 & 28 & 34 & \\
\hline 20 & 29 & 28 & 66 & 81 & 93 & 89 & 26 & 29 & 32 & 29 & 35 & \\
\hline 30 & 28 & 27 & 67 & 78 & 93 & 88 & 25 & 30 & 33 & 30 & 34 & \\
\hline 40 & 29 & 27 & 67 & 77 & 95 & 88 & 24 & 29 & 32 & 31 & 34 & \\
\hline 50 & 28 & 27 & 67 & 77 & 95 & 87 & 25 & 28 & 32 & 31 & 34 & \\
\hline 60 & 29 & 26 & 68 & 76 & 94 & 86 & 26 & 28 & 32 & 30 & 34 & \\
\hline 70 & 28 & 27 & 68 & 75 & 94 & 86 & 26 & 28 & 31 & 31 & 33 & \\
\hline 80 & 29 & 27 & 68 & 75 & 94 & 85 & 26 & 28 & 32 & 31 & 33 & \\
\hline 90 & 28 & 27 & 69 & 76 & 94 & 85 & 27 & 27 & 32 & 31 & 33 & \\
\hline 100 & 28 & 27 & 69 & 76 & 94 & 85 & 27 & 27 & 31 & 31 & 34 & \\
\hline \multicolumn{3}{|c|}{ ELEMENT } & \multicolumn{3}{|c|}{ SIGNAL } & \multicolumn{2}{|c|}{ B. G. } & \multicolumn{5}{|c|}{ SIGNAL-B. G. } \\
\hline $\mathrm{ZN}$ & \multicolumn{2}{|c|}{2139} & \multicolumn{3}{|c|}{63} & \multicolumn{2}{|c|}{28} & \multicolumn{5}{|c|}{34} \\
\hline $\mathrm{CD}$ & \multicolumn{2}{|c|}{2288} & \multicolumn{3}{|c|}{134} & \multicolumn{2}{|r|}{27} & \multicolumn{5}{|c|}{106} \\
\hline $\mathrm{MN}$ & \multicolumn{2}{|c|}{2795} & \multicolumn{3}{|c|}{139} & \multicolumn{2}{|r|}{69} & \multicolumn{5}{|c|}{70} \\
\hline $\mathrm{CU}$ & \multicolumn{2}{|c|}{3248} & \multicolumn{3}{|c|}{235} & \multicolumn{2}{|r|}{76} & \multicolumn{4}{|c|}{158} & \\
\hline $\mathrm{NI}$ & \multicolumn{2}{|c|}{3415} & \multicolumn{3}{|c|}{206} & \multicolumn{2}{|r|}{94} & \multicolumn{4}{|c|}{112} & \\
\hline $\mathrm{CO}$ & 3454 & & & 116 & & & 85 & & 30 & & & \\
\hline $\mathrm{AL}$ & 3962 & & & 96 & & & 27 & & 69 & & & \\
\hline $\mathrm{MN}$ & 4031 & & & 120 & & & 27 & & 92 & & & \\
\hline $\mathrm{PB}$ & 4058 & & & 39 & & & 31 & & 7 & & & \\
\hline $\mathrm{CR}$ & 4254 & & & 61 & & & 31 & & 30 & & & \\
\hline
\end{tabular}

\# $\quad$; the number of times of integration Concns.; $50 \mu \mathrm{gml}^{-1}$ for all elements

B. G. ; blank signals

lines are $\mathrm{Mn}$ [I] 403.076 and $279.482 \mathrm{~nm}$. These lines were selected because of a large difference in the upper level energy [13]. In this measurement, the background emission intensity is estimated as the mean value of those at wavelength in both sides $0.5 \mathrm{~nm}$ apart from the line of interest (Eq.3). After the data acquisition of the spectral intensities, the calculation of the excitation temperature is made (Eq.4). In the on-line and real-time mode, these processings are performed and 
Table 5 On-line and real-time measurement of the excitation temperature of Mn atoms in a H.C. L.

\begin{tabular}{|c|c|c|c|c|c|c|c|}
\hline \# & $a^{\prime}$ & $b^{\prime}$ & $c^{\prime}$ & $a$ & $b$ & $c$ & \\
\hline 1 & 231 & 659 & 663 & 431 & 1275 & 569 & $\mathrm{TA}=4273 \mathrm{~K}$ \\
\hline 2 & 307 & 689 & 543 & 415 & 1459 & 598 & $\mathrm{TA}=4293$ \\
\hline 3 & 296 & 675 & 538 & 471 & 1628 & 625 & $\mathrm{~T} A=4124$ \\
\hline 4 & 292 & 710 & 505 & 487 & 1738 & 604 & $\mathrm{TA}=4224$ \\
\hline 5 & 290 & 715 & 503 & 511 & 1829 & 598 & $\mathrm{TA}=4174$ \\
\hline 6 & 303 & 735 & 501 & 501 & 1981 & 630 & $\mathrm{TA}=4108$ \\
\hline 7 & 309 & 731 & 521 & 509 & 1968 & 641 & $\mathrm{TA}=4073$ \\
\hline 8 & 318 & 742 & 509 & 496 & 1973 & 636 & $\mathrm{TA}=4101$ \\
\hline 9 & 312 & 735 & 504 & 507 & 1991 & 632 & $T A=4086$ \\
\hline 10 & 314 & 731 & 498 & 498 & 2050 & 636 & $\mathrm{TA}=4033$ \\
\hline 11 & 311 & 751 & 491 & 496 & 2030 & 632 & $\mathrm{TA}=4124$ \\
\hline 12 & 314 & 762 & 489 & 494 & 2074 & 633 & $\mathrm{TA}=4125$ \\
\hline 13 & 317 & 766 & 486 & 491 & 2048 & 637 & $\mathrm{TA}=4159$ \\
\hline 14 & 324 & 759 & 482 & 500 & 2061 & 641 & $\mathrm{TA}=4127$ \\
\hline 15 & 325 & 767 & 478 & 495 & 2094 & 642 & $\mathrm{TA}=4129$ \\
\hline 16 & 324 & 771 & 477 & 492 & 2111 & 637 & $\mathrm{TA}=4130$ \\
\hline 17 & 325 & 762 & 475 & 505 & 2119 & 633 & $\mathrm{TA}=4105$ \\
\hline 18 & 330 & 765 & 473 & 500 & 2157 & 643 & $\mathrm{TA}=4082$ \\
\hline 19 & 327 & 762 & 471 & 501 & 2162 & 643 & $\mathrm{TA}=4079$ \\
\hline 20 & 336 & 764 & 474 & 497 & 2183 & 645 & $\mathrm{TA}=4050$ \\
\hline 80 & 363 & 836 & 479 & 498 & 2441 & 669 & $\mathrm{TA}=4056$ \\
\hline 81 & 363 & 844 & 479 & 498 & 2441 & 668 & $\mathrm{TA}=4074$ \\
\hline 82 & 363 & 842 & 479 & 498 & 2438 & 668 & $\mathrm{TA}=4072$ \\
\hline 83 & 362 & 848 & 480 & 498 & 2438 & 668 & $\mathrm{TA}=4085$ \\
\hline 84 & 361 & 847 & 482 & 498 & 2434 & 668 & $\mathrm{TA}=4085$ \\
\hline 85 & 362 & 847 & 481 & 497 & 2429 & 669 & $\mathrm{TA}=4088$ \\
\hline 86 & 361 & 848 & 481 & 496 & 2437 & 669 & $\mathrm{TA}=4087$ \\
\hline 87 & 361 & 851 & 481 & 496 & 2440 & 669 & $\mathrm{TA}=4092$ \\
\hline 88 & 361 & 855 & 480 & 496 & 2437 & 668 & $\mathrm{TA}=4104$ \\
\hline 89 & 360 & 853 & 480 & 496 & 2430 & 667 & $\mathrm{TA}=4106$ \\
\hline 90 & 361 & 855 & 481 & 496 & 2430 & 666 & $\mathrm{TA}=4109$ \\
\hline 91 & 360 & 854 & 479 & 498 & 2438 & 667 & $\mathrm{TA}=4106$ \\
\hline 92 & 360 & 856 & 478 & 497 & 2430 & 665 & $\mathrm{TA}=4115$ \\
\hline 93 & 361 & 859 & 478 & 497 & 2434 & 665 & $\mathrm{TA}=4119$ \\
\hline 94 & 362 & 857 & 477 & 495 & 2438 & 665 & $\mathrm{TA}=4111$ \\
\hline 95 & 363 & 857 & 476 & 495 & 2433 & 663 & $\mathrm{TA}=4113$ \\
\hline 96 & 363 & 856 & 477 & 494 & 2434 & 663 & $\mathrm{TA}=4108$ \\
\hline 97. & 363 & 854 & 480 & 496 & 2441 & 663 & $\mathrm{TA}=4096$ \\
\hline 98 & 363 & 855 & 480 & 496 & 2437 & 662 & $\mathrm{TA}=4102$ \\
\hline 99 & 362 & 853 & 479 & 496 & 2440 & 662 & $\mathrm{TA}=4098$ \\
\hline 100 & 362 & 853 & 479 & 497 & 2436 & 663 & $\mathrm{TA}=4099$ \\
\hline \multicolumn{3}{|c|}{$\begin{array}{l}\text { MN } 2795 \\
\text { MN } 4031\end{array}$} & \multicolumn{3}{|c|}{$\begin{array}{l}432.325 ; I_{2} \\
1855.81 ; I_{1}\end{array}$} & & \\
\hline
\end{tabular}

$\#$; the number of times of integration

$b$; the signal at Mn $I 279.482 \mathrm{~nm}$

$b^{\prime}$; at $\mathrm{Mn} \mathrm{I} 403.076 \mathrm{~nm}$

$a, a^{\prime}, c$ and $c^{\prime}$; at wavelengths $0.5 \mathrm{~nm}$ apart from the two lines

$\mathrm{TA}$; the excitation temperature of $\mathrm{Mn}, I_{1}=b-$ $(a+c) / 2, \quad I_{2}=b^{\prime}-\left(a^{\prime}+c^{\prime}\right) / 2 \quad$ Eq. 3, TA $=\left(E_{2}-E_{1}\right) /$ $k \ln \left(p_{1} \nu_{2} g_{2} A_{2} I_{1} / p_{2} \nu_{1} A_{1} I_{2}\right)$ Eq. 4 where $E$ is the upper level energy, $k$ the Bolzmann constant, $p$ the instrumental response factor involving those of the photomultiplier tube and the grating, $\nu$ the frequency, $g$ the statistical weight, $A$ the transition probability and $I$ the net intensity

The H. C. L. current $=15 \mathrm{~mA}$ d. c.
Table 6 Simultaneous determinations of the excitation temperatures of $\mathrm{Mn}$ and $\mathrm{Cr}$ atoms in the CMP

\begin{tabular}{rll}
\hline 1 & & \\
2 & $\mathrm{TMN}=6359$ & $\mathrm{TCR}=4019$ \\
3 & $\mathrm{TMN}=5310$ & $\mathrm{TCR}=2472$ \\
4 & $\mathrm{TMN}=5366$ & $\mathrm{TCR}=2206$ \\
5 & $\mathrm{TMN}=5974$ & $\mathrm{TCR}=2990$ \\
6 & $\mathrm{TMN}=5685$ & $\mathrm{TCR}=2932$ \\
7 & $\mathrm{TMN}=5698$ & $\mathrm{TCR}=3873$ \\
8 & $\mathrm{TMN}=5586$ & $\mathrm{TCR}=2946$ \\
9 & $\mathrm{TMN}=5605$ & $\mathrm{TCR}=3033$ \\
10 & $\mathrm{TMN}=5643$ & $\mathrm{TCR}=3081$ \\
11 & $\mathrm{TMN}=5516$ & $\mathrm{TCR}=3201$ \\
12 & $\mathrm{TMN}=5393$ & $\mathrm{TCR}=3186$ \\
13 & $\mathrm{TMN}=5416$ & $\mathrm{TCR}=3170$ \\
14 & $\mathrm{TMN}=5362$ & $\mathrm{TCR}=2992$ \\
15 & $\mathrm{TMN}=5515$ & $\mathrm{TCR}=2923$ \\
$\vdots$ & &
\end{tabular}

\# $\quad$; the number of times of integration

TMN; the excitation temperature of $\mathrm{Mn}$ atoms in $K$

TCR ; that of $\mathrm{Cr}$ atoms in $K$

The observed lines; Mn $I$ 403.076, $279.482 \mathrm{~nm}$, Cr $I$ 425.435, $391.916 \mathrm{~nm}$

The background correction was made as in Table 5 .

the results are printed out for every rotation of the grating, or $2 \mathrm{sec}$.

Table 6 gives another example of the excitation temperature measurement. The excitation temperatures of $\mathrm{Mn}$ and $\mathrm{Cr}$ atoms in the CMP are concurrently printed out. The concurrent measurement of excitation temperatures of multielement atoms and ions may give very useful clues for the diagnoses of plasma excitation sources and the associated interelement effects [14].

Figure 8 shows the example of the subtraction of background emission over the entire wavelength region from 210 to $550 \mathrm{~nm}$. The CMP was used as the excitation source. In order to evaluate the performance in correcting background emission, the sheath gas supply was intentionally stopped for the CMP to emit the intensive $\gamma$-band spectrum of NO molecules which were produced by the diffusion of air into the plasma and the subsequent reaction between $\mathrm{N}_{2}$ and $\mathrm{O}_{2}$ molecules. As seen from Fig. 8, the background (blank) emissions from 

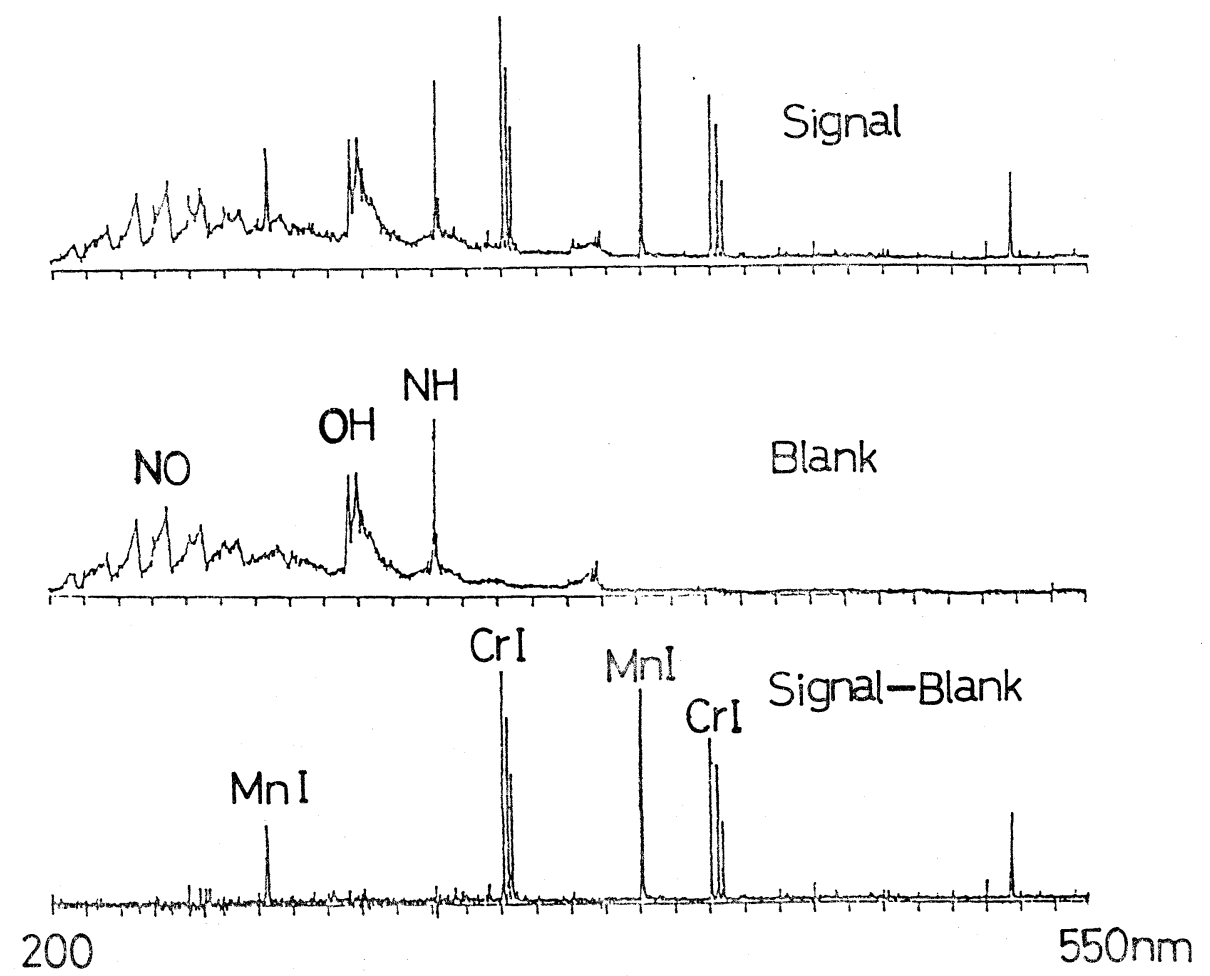

Fig. 8 Correction of background (blank) emission. The CMP was used as the excitation source. The number of times of integration: 50 . Mn: $50 \mu \mathrm{g} / \mathrm{ml}, \mathrm{Cr}: 10 \mu \mathrm{g} / \mathrm{ml}$.

$\mathrm{NO}, \mathrm{OH}$ and $\mathrm{NH}$ are fairly successfully corrected. However, the $\mathrm{S} / \mathrm{N}$ ratio is lower in the wavelength region where the background emission is strong. This may be attributed to the fluctuation in the wavelength synchronization. The more intensive becomes the background emission, the larger the magnitude of the erroneous signal. This can be also improved by making more precise the wavelength synchronization.

\section{Conclusion}

The novel type of rapid scanning spectrometer constructed for this study was evaluated for the use in AES. The sine-bar and its driving mechanisms were remove and the grating was directly driven at 30 r.p.m. by the synchronous motor. The wavelength synchronization was made by counting the pulses generated by the combination of the small tungsten lamp, the phototransistor and the aluminium disc with slots, which was attached to the shaft of the rotating grating. Owing to this design, the constructed spectrometer proved to have such an advantage that the entire spectra of all diffraction order from the zero to nth can be measured during one rotation of the grating. The adequately programmed microcomputer, dedicated to the spectrometer, allows various types of measurements in the on-line and real-time mode.

For the use in AES, however, the wavelength precision was not sufficient. The fluctuation is considered to be caused by the irregularity in the slot spacing of the aluminium synchronization disc and the instability in the grating rotation. Therefore, the improvement can be realized by making more precise the least significant synchronization digit. For this purpose, a promising alternative for the aluminium disc with the slots is the laser disc used for the video or audio memory medium (compact disc). On the laser disc, very small spots of a few $\mu \mathrm{m}$ length and sub $\mu \mathrm{m}$ width are deposited in order to register 
information. By counting the spots with a commercially available laser pick up device, the desired direct synchronization of order of $0.01 \mathrm{~nm}$ may be attainable. Such a spectrometer, so to speak, a laser disc-synchronized rapid scanning spectrometer is currently under investigation.

Another problem is that the time duty per a unit wavelength is short for the rapid scanning spectrometer. The peak intensity loss is not so notable for the relatively intensive light source (ca. $50 \%$ shown in the result). However, the weaker the source intensity becomes, the more significant the loss will become. So, the absolute intensity of the excitation source is important. A possible way to increase the time duty is to use sector back and forth motion of the aluminium synchronization disc, instead of the 360 degree rotation. The motion can be used within the wavelength range of interest. Up-down counters can tell the wavelength. In this synchronization mode, however, real-time processing of the acquired data is hard because of the limited cpu speed.

\section{Acknowledgments}

The authors would like to thank Mr. T. Imura and Mr. T. Watanabe for skillful the glass blowing of the desolvation system, Mr. S. Takahashi and Mr. S. Sakai for the elaborate manufacture of the aluminium synchronization disc and Prof. S. Tsuge for helpful advice. This work has been supported partly by the Grant-in-Aid from the Ministry of Education of Japan and partly by the Sakkokai Foundation.

\section{References}

1) D. J. Johnson, F.W. Planckey and J.D. Winefordner, Anal. Chem., 47 (1975) 1739.

2) V.A. Fassel, Anal. Chem., 51 (1979) 1302A.

3) G. Horlick and E. G. Codding, Anal. Chem., 45 (1973) 1490.

4) Y. Talmi, Anal. Chem., 47 (1974) 685A.

5) K.W. Busch, N.G. Howell and G.H. Morrison, Anal. Chem., 46 (1974) 575.

6) J.W. Strojek, G.A. Gruver and T. Kuwana, Anal. Chem., 41 (1969) 481.

7) O. Rose, Jr., W.R. Heineman, J. A. Caruso and F. L. Fricke, Analyst, 103 (1978) 113.

8) K. J. Mulligan, M. Zerezhgi and J.A. Caruso, Spectrochim. Acta, 38B (1983).

9) K. Usami, K. Kitagawa and S. Tsuge, Abstract, 18th Tokyo Conf. on Appl. Spectrsc., Tokyo, Nov., 1982, p. 66.

10) T. Shimizu, H. Arita and K. Sakai, Bunseki Kagaku, 32 (1983) E85.

11) K. Kitagawa, K. Uchino, K. Ohishi and K. Yasuda, Abstract, 23rd Ann. Meeting of Jpn. Soc. for Anal. Chem., Suita Osaka, Nov., 1974, p. B117.

12) L.S. Ornstein and H. Brinkman, K. Akad. Amsterdam, 34 (1931) 33.

13) K. Kitagawa and T. Takeuchi, Anal. Chim. Acta, 60 (1972) 309.

14) K. Kitagawa and T. Takeuchi, Anal. Chim. Acta, 67 (1973) 453.

15) A. N. Zaidel, V. K. Prokofev and S. M. Raiskii, Table of Spectrum Lines, Pergamon Press, 1961. 